\title{
Simultaneous Liver-Kidney Transplantation: A Survey of US Transplant Centers
}

\author{
M. K. Nadima,*, C. L. Davis ${ }^{b}$, R. Sung ${ }^{\text {, }}$, \\ J. A. Kellum ${ }^{d}$ and Y. S. Genyk \\ a Division of Nephrology, Department of Medicine, \\ University of Southern California, Los Angeles, CA \\ ${ }^{b}$ Division of Nephrology, Department of Medicine, \\ University of Washington, Seattle, WA \\ c Section of Transplantation Surgery, Department of \\ Surgery, University of Michigan, Ann Arbor, MI \\ dDepartment of Critical Care, University of Pittsburgh, \\ Pittsburgh, PA \\ 'Division of Abdominal Organ Transplantation Surgery, \\ Department of Surgery, University of Southern California, \\ Los Angeles, CA \\ *Corresponding author: Mitra K. Nadim, nadim@usc.edu
}

Consensus recommendations have been published to help better define those patients who would benefit from simultaneous liver-kidney transplantation (SLK). We conducted a survey of transplant centers that perform SLK ( $n=88,65 \%$ response rate) to determine practice patterns in the United States. The majority of centers $(73 \%)$ stated that they use dialysis duration whereas only $30 \%$ of centers use acute kidney injury duration as a criterion for determining need for SLK. Dialysis duration $>4$ weeks was used by $32 \%$ of centers, $>6$ weeks by $37 \%$ and $>8$ weeks by $32 \%$ of centers. Glomerular filtration rate (GFR) was estimated using the modified diet in renal disease (MDRD)-4 equation in roughly half of centers whereas the MDRD6 equation was used by only $6 \%$. In patients with chronic kidney disease, GFR $<40 \mathrm{~mL} / \mathrm{min}$ was used by $24 \%$ of centers as a criterion for SLK transplants instead of the recommended threshold of $<30 \mathrm{~mL} / \mathrm{min}$. Regional differences in practices were also observed. This survey demonstrates significant variation in the criteria used for SLK among transplant centers, with few centers following the current published recommendations, and emphasizes the need for evidencebased guidelines and uniformity in studying renal dysfunction in liver transplant candidates.

Key words: Acute kidney injury, national survey, OPTN, simultaneous liver-kidney transplantation

Abbreviations: AKI, acute kidney injury; CKD, chronic kidney disease; GFR, glomerular filtration rate; MDRD, modified diet in renal disease; MELD, model for endstage liver disease; OPTN, Organ Procurement and Transplantation Network; Scr, serum creatinine; SLK, simultaneous liver kidney.
Received 07 March 2012, revised 30 April 2012 and accepted for publication 19 May 2012

\section{Introduction}

Acute kidney injury (AKI) is common in patients with end stage liver disease with an estimated prevalence of $30 \%$ at the time of liver transplantation (LT; Refs. 1-3). Simultaneous liver-kidney transplantation (SLK) remains the procedure of choice for patients with both liver and kidney failure. However, renal dysfunction in these patients is neither singular in etiology, nor uniform in recoverability; the level and duration of renal dysfunction (including renal replacement therapy) beyond which renal recovery is not possible following liver transplantation alone (LTA) are unknown. Several investigators have studied the impact of pretransplant AKI on posttransplant outcomes (3-21). However, systematic evaluation of the literature is hindered by the lack of precise classification of the severity or cause of renal dysfunction, variations in the definitions used to describe renal dysfunction, the presence of underlying chronic kidney disease (CKD) and unmeasured variations in practice. The conflicting results in the literature are also likely due to other reasons such as small study sample size, retrospective design and reporting bias. Furthermore, this lack of standardization has made it difficult for transplant programs to develop evidence-based patient management strategies. In short, on the basis of existing literature, it is difficult to predict the long-term outcomes of liver transplant patients who have been transplanted in the context of acute and/or chronic pretransplant renal dysfunction.

Since the implementation of the model for end-stage liver disease (MELD) scoring system in 2002 by the Organ Procurement and Transplantation Network (OPTN), the percent of SLK has increased across the United States (US) (Figure 1). In response to the increase in SLK during the MELD era, two consensus meetings were organized to develop recommendations and to standardize the evaluation and selection of candidates for SLK $(22,23$; Table 1). Subsequently, in 2009, the OPTN Kidney and Liver Intestinal Organ Transplantation Committees set forth a proposal for minimum kidney listing criteria for candidates listed for SLK, with the goal of improving patient and renal graft survival following SLK while limiting unnecessary kidney transplants (Table 1). Despite the current 


\section{Nadim et al.}

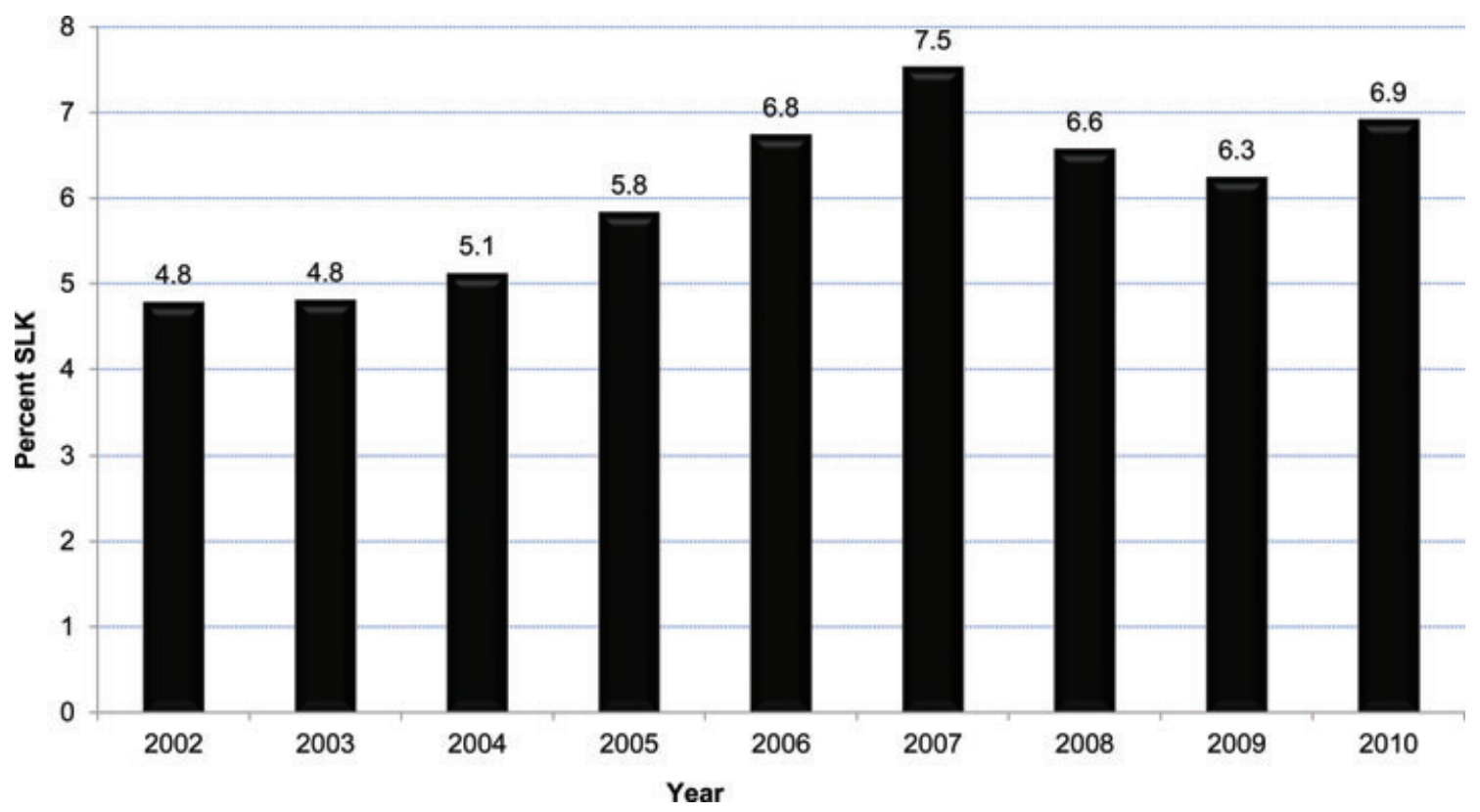

Figure 1: Percentage of simultaneous liver-kidney transplantation (SLK) of all deceased donor, adult liver transplantation. Data from Organ Procurement and Transplantation Network (http://optn.transplant.hrsa.gov) as of June 2011.

recommendations, it is unclear whether these guidelines or proposed policy represent actual practice. OPTN data demonstrate significant regional variability in the rate of SLK, which may reflect the variability in patient acuity of the liver transplant waitlist in various UNOS regions (Figure 2).
As the frequency of renal dysfunction in waitlisted liver transplant candidates continues to increase in several OPTN regions, the issue of whether patients should receive SLK continues to confront the transplant community and uncertainty exists despite the published recommendations. To assess the practice differences and regional

Table 1: Published guidelines and OPTN proposed policy on simultaneous liver-kidney transplantation

\begin{tabular}{|c|c|}
\hline Author & Recommendations \\
\hline Eason et al. (2008)(23) & $\begin{array}{l}\text { a. Patients with end-stage renal disease } \\
\text { b. Patients with } \mathrm{CKD} \text { with } \mathrm{GFR} \leq 30 \mathrm{~mL} / \mathrm{min} \\
\text { c. Patients with } \mathrm{AKI} / \mathrm{HRS} \text { with } \mathrm{Scr} \geq 2 \mathrm{mg} / \mathrm{dL} \text { or dialysis } \geq 8 \text { weeks } \\
\text { d. Patients with evidence of } \mathrm{CKD} \text { and kidney biopsy demonstrating }>30 \% \text { glomerulosclerosis } \\
\text { or } 30 \% \text { fibrosis } \\
\text { Other criteria recommended are the presence of comorbidities such as diabetes, hypertension, } \\
\text { age }>65 \text {, other preexisting renal disease along with proteinuria, renal size and duration of } \\
\text { elevated } \mathrm{Scr}\end{array}$ \\
\hline $\begin{array}{l}\text { OPTN Kidney Transplantation } \\
\text { Committee and the Liver and } \\
\text { Intestinal Organ Transplantation } \\
\text { Committee Policy 3.5.10 (2009) }\end{array}$ & $\begin{array}{l}\text { a. CKD requiring dialysis with documentation of the CMS form } 2728^{1} \\
\text { b. CKD (GFR }<=30 \mathrm{~mL} / \mathrm{min} \text { by MDRD6 or iothalamate measurement and proteinuria }>3 \mathrm{~g} / \text { day } \\
\text { c. Sustained AKI requiring dialysis for } 6 \text { weeks or more (defined as dialysis at least twice per } \\
\text { week for } 6 \text { consecutive weeks) } \\
\text { d. Sustained AKI (GFR } \leq 25 \mathrm{~mL} / \mathrm{min} \text { for } 6 \text { weeks or more by MDRD6 or direct measurement) } \\
\text { not requiring dialysis } \\
\text { e. Sustained AKI: Patients may also qualify for SLK listing with a combination of time in } \\
\text { categories (c) and (d) above for a total of six weeks (e.g. patients with a GFR }<25 \mathrm{~mL} / \mathrm{min} \\
\text { for } 3 \text { weeks followed by dialysis for } 3 \text { weeks). } \\
\text { f. Metabolic disease }\end{array}$ \\
\hline
\end{tabular}

OPTN = Organ Procurement and Transplantation Network; CKD = chronic kidney disease; AKI = acute kidney injury; HRS = hepatorenal syndrome; GFR = glomerular filtration rate; SLK = simultaneous liver-kidney transplantation; CMS = Center for Medicare and Medicaid services.

${ }^{1} \mathrm{CMS}$ form 2728: Form required by Medicare \& Medicaid to stating that a dialysis patient has end-stage renal disease with no chance of renal recovery. 


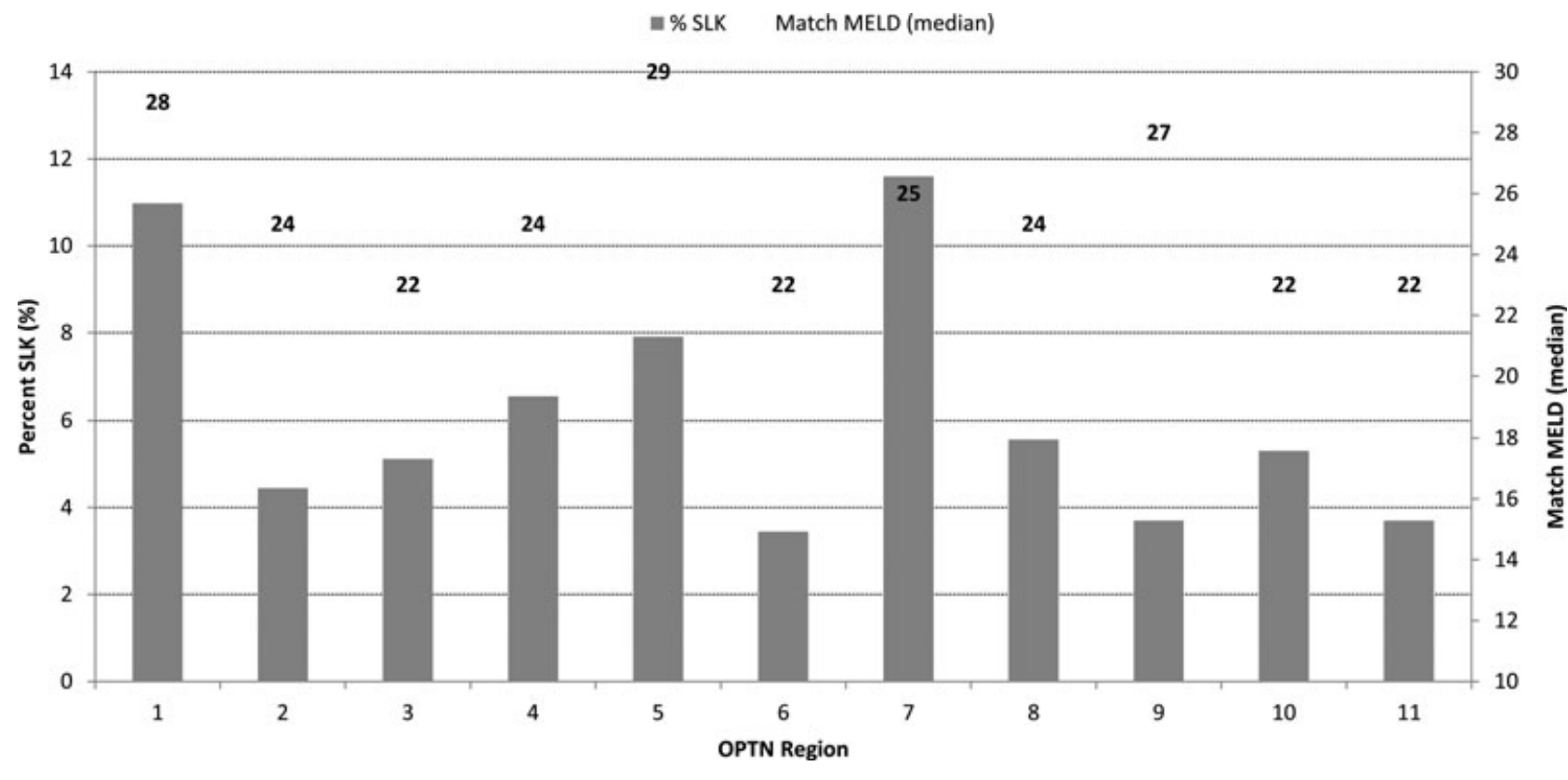

Figure 2: Percentage of simultaneous liver-kidney transplantation (SLK) of all deceased donor, adult liver transplantation in each Organ Procurement and Transplantation Network (OPTN) region from 2002-2010. Data from OPTN (http://optn.transplant.hrsa.gov) as of June 2011.

variability in SLK, we sent out a questionnaire to all US transplant programs that performed SLK.

\section{Methods}

United States centers that performed SLK transplantation were identified from the OPTN website (http://optn.transplant.hrsa.gov). Centers that performed $<15 \mathrm{LT}$ each year or did not perform at least 1 SLK during the 2 years before the survey were excluded. A web-based questionnaire, which included 18 questions, was developed by the authors via Survey Monkey (www.surveymonkey.com) and sent to the Medical Directors of the Kidney Transplant program in each of the identified centers ( $n=88$; Table 2). The survey was initially pilot-tested by sending it to 10 Medical Directors to make sure that it was feasible and understandable. Survey items were modified based on feedback obtained on the following elements: content validity, presentation of information and the ability of survey respondent to interpret the essential information and understand each item. Once we received the response from the initial 10 centers, the survey was then distributed to the remaining 78 centers. The survey was sent out, via email March 2011 and responses were collected over the following 3 months with two reminder emails sent during that time. To increase response rates, the survey was anonymous and therefore, with the exception of regional designation, the identities of the participating centers, their cities and states are unknown.

Survey responses were coded and analyses were conducted using the Statistical Analysis Software. Data are expressed as means and medians or the percentage of centers with specific responses. Survey responses were also examined by MELD regions. The OPTN regions were cohorted into three groups: Low MELD (regions 3, 6, 10 and 11), Average MELD (regions 2, 4 7 and 8) and High MELD (1, 5 and 9). These cut-off points were obtained and selected based on the OPTN data for median MELD of patients at the time of LTA from 2002-2010 (http://optn.transplant.hrsa.gov). We used the
Cochran-Mantel-Haenszel (CMH) test to compare the regional differences in listing criteria for SLK by median MELD. Our outcome measures were: yearly number of SLK transplants performed, duration of dialysis, AKI duration (not on dialysis), AKI glomerular filtration rate (GFR) threshold and CKD GFR threshold. To measure the consistency among centers we dichotomized our variables based on our definition of leniency. Leniency was defined in this study as a center that selected any of the following measures: $>$ 4weeks dialysis duration, >10SLK/year, AKI and CKD GFR threshold of $>25 \mathrm{~mL} / \mathrm{min}$ and $>30 \mathrm{~mL} / \mathrm{min}$, respectively. We ran $\mathrm{CMH}$ tests comparing our independent variable dialysis duration in weeks to our outcome variables: annual number of LT and SLKs performed, AKI duration in weeks, $\mathrm{AKI}$ and CKD GFR threshold ( $\mathrm{mL} / \mathrm{min}$ ). In addition, we performed $\mathrm{CMH}$ tests using the number of SLKs performed per year as the independent variable and number of liver transplants per year, dialysis and AKI duration in weeks, AKI and CKD GFR threshold ( $\mathrm{mL} / \mathrm{min}$ )as our outcome measures. A $p$ value $<0.05$ was considered significant.

\section{Results}

\section{Characteristics of programs}

From the 88 centers surveyed, 57 centers responded for a response rate of $65 \%$. Characteristics of the programs that completed the survey are listed in Table 3. All 11 OPTN regions were represented with a response rate of $\geq 50 \%$ in all regions except for region 7 (44\%). Forty percent of centers performed on average 50-100 liver transplants a year. The majority of centers performed $<10$ SLK/year (90\%) with only six centers $(10 \%)$ performing $>10$ SLK transplants a year. Four of the six centers that performed $>10$ SLK/year also performed $>100$ liver transplants/year. The decision to perform SLK was made by both the transplant nephrologist and surgeon in $67 \%$ of centers, by the transplant 


\section{Nadim et al.}

Table 2: Survey questions

Questions

2. On average, how many liver transplants does your center perform each year?

3. On average, how many SLK transplants does your center perform each year?

4. Rate the following criteria you use at your center to decide the need for SLK:
a. Dialysis duration
b. AKI, not on dialysis
c. Kidney biopsy

5. What duration of AKI, with or without dialysis do you use at your center to consider patients for SLK?

6. What GFR level do you use to select candidates for SLK who have:
a. AKI, not on dialysis
b. CKD

7. Rate the methods you use at your center to determine GFR in patients with cirrhosis:
a. Iothalamate
b. 24-h urine collection for $\mathrm{CrCl}$
c. MDRD-4 equation
d. MDRD-6 equation

8. In the absence of classic indications (potassium, acidosis, diuretic resistant fluid overload, etc.) rate whether or not you initiate dialysis on your patients with cirrhosis for the following indications:
a. RIFLE creatinine/GFR criteria
b. RIFLE urine output criteria
c. Diuretic responsive fluid overload

9. How do you define AKI in patients with cirrhosis?

10. Who makes the final decision regarding the need for SLK at your center?

\section{Possible answers}

Region 1: CT, MA

Region 2: DC, MD, NJ, PA

Region 3: AL, AR, FL, GA, LA

Region 4: OK, TX

Region 5: CA, AZ, UT

Region 6: OR, WA

Region 7: IL, MN, WI

Region 8: CO, IA, KS, MO, NE

Region 9: NY

Region 10: IN, MI, OH

Region 11: KY, NC, SC, TN, VA

a. $<50$

b. $50-100$

c. $>100$

a. $<5$

b. $5-10$

c. $>10$

a. Always

b. Sometimes

c. Rarely

d. Never

a. 4 weeks

b. 6 weeks

c. 8 weeks

d. Not applicable

a. $<40 \mathrm{~mL} / \mathrm{min}$

b. $<30 \mathrm{~mL} / \mathrm{min}$

c. $<25 \mathrm{~mL} / \mathrm{min}$

d. Not applicable

a. Always

b. Sometimes

c. Rarely

d. Never
a. Always
b. Sometimes
c. Rarely
d. Never
a. Scr $>1.5 \mathrm{mg} / \mathrm{dL}$
b. Scr $>2.0 \mathrm{mg} / \mathrm{dL}$
c. $\uparrow$ Scr by $50 \%$ from baseline
d. $\uparrow$ Scr by $100 \%$ from baseline
e. Other
a. Transplant Nephrologist
b. Transplant Surgeon
c. Both

$\mathrm{CT}=$ Connecticut; $\mathrm{MA}=$ Massachusetts; $\mathrm{DC}=$ District of Columbia; $\mathrm{MD}=$ Maryland; NJ = New Jersey; PA = Pennsylvania; $\mathrm{AL}=$ Alabama; $\mathrm{AR}=$ Arkansas; $\mathrm{FL}=$ Florida; $\mathrm{GA}=$ Georgia; $\mathrm{LA}=$ Louisiana; $\mathrm{OK}=$ Oklahoma; $\mathrm{TX}=$ Texas; $\mathrm{CA}=\mathrm{California} ; \mathrm{AZ}=\mathrm{Arizona}$; $\mathrm{UT}=$ Utah; $\mathrm{OR}=$ Oregon; WA = Washington; IL = Illinois; $\mathrm{MN}=$ Minnesota; $\mathrm{WI}=$ Wisconsin; $\mathrm{CO}=$ Colorado; IA = Iowa; KS = Kansas; $\mathrm{MO}=$ Missouri; NE = Nebraska; NY = New York; IN = Indiana; MI = Michigan; OH = Ohio; KY = Kentucky; NC = North Carolina; SC = South Carolina; $\mathrm{TN}=$ Tennessee; $\mathrm{VA}=$ Virginia GFR = glomerular filtration rate; $\mathrm{CrCl}=$ creatinine clearance; $\mathrm{MDRD}=$ modified diet in renal disease; SLK = simultaneous liver-kidney; $A K I=$ acute kidney injury; RRT = renal replacement therapy; RIFLE = risk, injury, failure, loss, endstage; Scr = serum creatinine. 
Table 3: Transplant program characteristics (based on 57 responses)

\begin{tabular}{lr}
\hline & $\mathrm{N}(\%)$ \\
\hline UNOS Region—\# of responders/\# surveyed in each region $(\%)$ : \\
a. Region 1 & $3 / 6(50)$ \\
b. Region 2 & $8 / 9(89)$ \\
c. Region 3 & $8 / 11(73)$ \\
d. Region 4 & $6 / 9(67)$ \\
e. Region 5 & $8 / 13(62)$ \\
f. Region 6 & $2 / 3(67)$ \\
g. Region 7 & $4 / 9(44)$ \\
h. Region 8 & $3 / 6(50)$ \\
i. Region 9 & $4 / 5(80)$ \\
j. Region 10 & $6 / 7(86)$ \\
k. Region 11 & $5 / 10(50)$
\end{tabular}

Annual number of LT performed—\# based on response/\# based on OPTN ${ }^{1}$ :
a. $<50$
b. $50-100$
c. $>00$

20/36 (56)

$23 / 32(72)$

$14 / 17(82)$

Annual number of SLK performed-\# based on response/\# based on OPTN ${ }^{1}$ :
a. $<5$
b. $5-10$
$24 / 55(44)$
c. $>10$
$27 / 27(100)$ $6 / 6(100)$

$\mathrm{LT}=$ liver transplant; SLK = simultaneous liver kidney.

${ }^{1}$ Based on OPTN data for 2010 (http://optn.transplant.hrsa.gov).

nephrologist alone in $28 \%$ of centers and by the transplant surgeon alone in $5 \%$.

\section{Patients with AKI}

The definition of AKI used by centers for patients with cirrhosis varied. AKI was defined as a minimum increase in serum creatinine (Scr) of $50 \%$ from baseline by $67 \%$ of Medical Directors, Scr increase of $100 \%$ from baseline by $9 \%$, Scr increase of $25 \%$ by $5 \%$ and absolute values of Scr $>1.5 \mathrm{mg} / \mathrm{dL}$ and $\mathrm{Scr}>2 \mathrm{~m} / \mathrm{dL}$ by $14 \%$ and $5 \%$ of Medical
Directors, respectively. Seventy percent of respondents stated that they also used duration of AKI for patients not on dialysis to determine candidates for SLK with a duration of $A K I>8$ weeks used in most centers (Table 4).

Among candidates with AKI on dialysis, $73 \%$ of centers used dialysis duration to determine candidacy for SLK transplantation (Table 4). Dialysis duration of $>4$ weeks was used in $32 \%$ of centers, $>6$ weeks in $38 \%$ and $>8$ weeks in $30 \%$ of centers. When asked about indications for initiation of dialysis outside the classic indications for dialysis (hyperkalemia, acidosis, diuretic resistant fluid overload, etc.), the majority of centers did not use either RIFLE criteria (Scr or urine output) or diuretic responsive fluid overload as an indication to initiate dialysis (Table 4).

\section{GFR determination}

Over $60 \%$ of centers rarely or never used either iothalamate $(62 \%)$ or modified diet in renal disease (MDRD) equation $6(67 \%)$ to determine GFR in patients with cirrhosis (Table 4), and the majority of centers used the MDRD-4 equation (77\%). In regards to GFR threshold in patients with $\mathrm{AKI}$ as a selection criteria for SLK, 12\% used GFR threshold $<40 \mathrm{~mL} / \mathrm{min}, 18 \%$ used GFR $<30 \mathrm{~mL} / \mathrm{min}, 5 \%$ used GFR $<25 \mathrm{~mL} / \mathrm{min}$, and $16 \%$ used GFR $<20 \mathrm{~mL} / \mathrm{min}$ (Figure 4). Sixty percent did not use GFR threshold in patients with $A K I$ to select patients for SLK. In patients with CKD, the majority of centers $(53 \%)$ followed the current recommendations of using $\mathrm{GFR}<30 \mathrm{~mL} / \mathrm{min}$ as a threshold (Table 4).

\section{Variations based on OPTN region}

Regional variation was observed with respect to several of the current SLK recommendations (Table 5). There was regional variation with respect to dialysis duration, with $>$ $50 \%$ of the centers in Region 5 and 11 using dialysis duration of $>4$ weeks. A higher percent of centers in Region 11 also reported using a GFR threshold of $<40 \mathrm{~mL} / \mathrm{min}$

Table 4: Management practices for liver transplant candidates with renal dysfunction

\begin{tabular}{|c|c|c|c|c|}
\hline & $\begin{array}{l}\text { Always } \\
\mathrm{N}(\%)\end{array}$ & $\begin{array}{c}\text { Sometimes } \\
N(\%)\end{array}$ & $\begin{array}{l}\text { Rarely } \\
\text { N (\%) }\end{array}$ & $\begin{array}{l}\text { Never } \\
\text { N (\%) }\end{array}$ \\
\hline \multicolumn{5}{|c|}{ Methods used to determine GFR in patients with cirrhosis $(n=57)$} \\
\hline lothalamate & $5(9)$ & $16(28)$ & $14(25)$ & 22 (39) \\
\hline 24-h urine collection for $\mathrm{CrCl}$ & $15(26)$ & $25(44)$ & $15(26)$ & $2(4)$ \\
\hline MDRD-4 equation & $22(39)$ & $20(35)$ & $4(7)$ & $11(19)$ \\
\hline MDRD-6 equation & $3(5)$ & $16(28)$ & $15(26)$ & $23(40)$ \\
\hline \multicolumn{5}{|c|}{ Criteria used to determine SLK candidacy $(n=57)$} \\
\hline Dialysis duration & $42(74)$ & $14(25)$ & $1(2)$ & $0(0)$ \\
\hline AKI, not on dialysis & $17(30)$ & $23(40)$ & $11(19)$ & $6(11)$ \\
\hline Kidney biopsy & $2(4)$ & $19(33)$ & $32(56)$ & $4(7)$ \\
\hline \multicolumn{5}{|c|}{ Criteria used to initiate RRT in patients with cirrhosis $(n=57)$} \\
\hline RIFLE Scr criteria & $7(12)$ & $16(28)$ & $16(28)$ & $18(32)$ \\
\hline RIFLE urine output criteria & $4(7)$ & $26(46)$ & $12(21)$ & $15(26)$ \\
\hline Diuretic responsive fluid overload & $1(2)$ & $13(23)$ & $26(46)$ & $17(30)$ \\
\hline
\end{tabular}

GFR = glomerular filtration rate; $\mathrm{CrCl}=$ creatinine clearance; MDRD = modified diet in renal disease; SLK = simultaneous liver kidney; $\mathrm{AKI}=$ acute kidney injury; RRT = renal replacement therapy; RIFLE = risk, injury, failure, loss, endstage; Scr = serum creatinine. 
Table 5: Regional differences in listing criteria for simultaneous liver-kidney transplantation

\begin{tabular}{|c|c|c|c|c|c|c|c|c|c|c|c|c|}
\hline & \multicolumn{12}{|c|}{ UNOS Region } \\
\hline & $\begin{array}{c}\text { All } \\
(n=57)\end{array}$ & $\begin{array}{c}1 \\
(n=3)\end{array}$ & $\begin{array}{c}2 \\
(n=8)\end{array}$ & $\begin{array}{c}3 \\
(n=8)\end{array}$ & $\begin{array}{c}4 \\
(n=6)\end{array}$ & $\begin{array}{c}5 \\
(n=8)\end{array}$ & $\begin{array}{c}6 \\
(n=2)\end{array}$ & $\begin{array}{c}7 \\
(n=4)\end{array}$ & $\begin{array}{c}8 \\
(n=3)\end{array}$ & $\begin{array}{c}9 \\
(n=4)\end{array}$ & $\begin{array}{c}10 \\
(n=6)\end{array}$ & $\begin{array}{c}11 \\
(n=5)\end{array}$ \\
\hline MELD Median $^{1}$ & 24 & 28 & 24 & 22 & 24 & 29 & 22 & 25 & 24 & 27 & 22 & 22 \\
\hline \multicolumn{13}{|c|}{ Dialysis duration-\% } \\
\hline$>4$ weeks & 32 & 33 & 25 & 38 & 17 & 63 & 0 & 25 & 33 & 0 & 17 & 60 \\
\hline$>6$ weeks & 37 & 33 & 25 & 13 & 33 & 0 & 100 & 50 & 67 & 100 & 50 & 40 \\
\hline$>8$ weeks & 32 & 33 & 50 & 50 & 50 & 38 & 0 & 25 & 0 & 0 & 33 & 0 \\
\hline \multicolumn{13}{|c|}{ AKI duration (not on dialysis)—\% } \\
\hline$>4$ weeks & 14 & 33 & 38 & 13 & 0 & 25 & 0 & 0 & 0 & 0 & 0 & 20 \\
\hline$>6$ weeks & 12 & 0 & 0 & 25 & 17 & 25 & 0 & 0 & 0 & 25 & 0 & 20 \\
\hline$>8$ weeks & 44 & 33 & 38 & 50 & 50 & 25 & 50 & 50 & 33 & 25 & 83 & 40 \\
\hline Never & 30 & 33 & 25 & 13 & 33 & 25 & 50 & 50 & 67 & 50 & 17 & 20 \\
\hline \multicolumn{13}{|c|}{ AKI GFR threshold—\% } \\
\hline$<40 \mathrm{~mL} / \mathrm{min}$ & 12 & 0 & 25 & 13 & 17 & 0 & 0 & 0 & 0 & 0 & 17 & 40 \\
\hline$<30 \mathrm{~mL} / \mathrm{min}$ & 19 & 33 & 13 & 25 & 17 & 0 & 0 & 50 & 33 & 0 & 33 & 20 \\
\hline$<25 \mathrm{~mL} / \mathrm{min}$ & 5 & 0 & 13 & 13 & 0 & 13 & 0 & 0 & 0 & 0 & 0 & 0 \\
\hline$<20 \mathrm{~mL} / \mathrm{min}$ & 16 & 33 & 13 & 13 & 33 & 13 & 0 & 50 & 0 & 25 & 17 & 20 \\
\hline Not applicable & 47 & 33 & 38 & 38 & 33 & 75 & 100 & 0 & 67 & 75 & 33 & 20 \\
\hline \multicolumn{13}{|c|}{ CKD GFR threshold—\% } \\
\hline$<40 \mathrm{~mL} / \mathrm{min}$ & 25 & 0 & 25 & 25 & 17 & 38 & 0 & 25 & 33 & 25 & 0 & 60 \\
\hline$<30 \mathrm{~mL} / \mathrm{min}$ & 53 & 100 & 63 & 25 & 33 & 25 & 100 & 75 & 67 & 25 & 100 & 40 \\
\hline$<25 \mathrm{~mL} / \mathrm{min}$ & 7 & 0 & 13 & 13 & 17 & 0 & 0 & 0 & 0 & 25 & 0 & 0 \\
\hline$<20 \mathrm{~mL} / \mathrm{min}$ & 12 & 0 & 0 & 25 & 33 & 25 & 0 & 0 & 0 & 25 & 0 & 0 \\
\hline Not applicable & 4 & 0 & 0 & 13 & 0 & 13 & 0 & 0 & 0 & 0 & 0 & 0 \\
\hline
\end{tabular}

MELD = model for end-stage liver disease; $\mathrm{AKI}=$ acute kidney injury; GFR = glomerular filtration rate; CKD = chronic kidney disease.

${ }^{1}$ Data based on OPTN 2002-2010 in adult patients receiving deceased donor liver transplantation (http://optn.transplant.hrsa.gov)

in their patients with AKI or CKD in comparison to other regions in the nation.

Median MELD of adult patients who underwent deceased donor LT between 2002 and 2010 in the low MELD regions was 22, 24 in the average MELD regions and 28 in the high MELD regions. A higher percentage of centers located in the high MELD regions used AKI duration (with or without dialysis) of $>4$ weeks, and a GFR threshold of $<40 \mathrm{~mL} / \mathrm{min}$ in comparison to the low and average MELD regions (Table 6).

\section{Consistency of center practices}

Centers that were lenient on dialysis duration, that is, $>4$ weeks, were also significantly more lenient on measures such as annual number of SLK $>10$, AKI duration $>4$ weeks and CKD GFR threshold of $>30 \mathrm{~mL} / \mathrm{min}$, than those centers that were more restrictive on dialysis duration ( $>6$ weeks; Table 7). Centers that perform >10 SLK annually were significantly more likely to have performed over 100 liver transplants and use a lenient dialysis duration ( $>4$ weeks duration) but not lenient criteria for AKI duration or thresholds for AKI and CKD GFR (data not shown).

\section{Discussion}

This is the first national survey aimed at determining the practices used at US centers to determine the need for SLK in patients awaiting LT. Our results demonstrate the lack of consistency amongst centers in their criteria used to select candidates for SLK transplantation. Moreover, many centers do not follow the current published recommendations or the proposed OPTN listing criteria for SLK transplantation. The variability in the responses could be related not only to the acuity of patients on the waitlist in each region, but also due to several pitfalls in the existing guidelines that make it difficult to accurately distinguish candidates that will benefit from SLK from those that will not. These include the definition of AKI, GFR determination and the duration of $A K I$, with or without dialysis.

The evolution of renal dysfunction in the context of liver failure ranges from insidious to rapid, mild to severe. Its development adds an element of urgency on behalf of the patient and strategic complexity on behalf of the program to make appropriate and timely decisions. Establishing transplant algorithms for dual organ failure depends on our ability to predict whether renal function will improve, stabilize or continue to progress following transplantation and to what extent renal transplant might influence the outcome of the liver transplant. For those at risk for nonrecovery of renal function, SLK may be justified. However, the key factors that determine nonrecovery with a high degree of predictive value remain poorly defined. Performing an unnecessary kidney transplant also removes available kidneys from the pool of organs for isolated kidney recipients, while failing to provide a kidney during combined 
SLK Practice in US Transplant Centers

Table 6: Regional differences in listing criteria for simultaneous liver-kidney transplantation by median MELD in region

\begin{tabular}{|c|c|c|c|c|c|}
\hline & $\begin{array}{c}\text { All } \\
(n=57)\end{array}$ & $\begin{array}{l}\text { Low MELD } \\
\text { regions }^{1}(n=21)\end{array}$ & $\begin{array}{l}\text { Average MELD } \\
\text { regions }^{2}(n=21)\end{array}$ & $\begin{array}{c}\text { High MELD } \\
\text { regions }^{3}(n=15)\end{array}$ & p-Value \\
\hline MELD Median ${ }^{1}$ & 24 & 22 & 24 & 28 & \\
\hline \multicolumn{5}{|c|}{ Annual number of SLK performed-n (\%) } & 0.59 \\
\hline$<5$ & $24(42)$ & $10(48)$ & $7(33)$ & $7(47)$ & \\
\hline $5-10$ & $27(47)$ & $9(43)$ & $13(62)$ & $5(33)$ & \\
\hline$>10$ & $6(10)$ & $2(10)$ & $1(5)$ & $3(20)$ & \\
\hline \multicolumn{5}{|c|}{ Dialysis duration-n (\%) } & 0.83 \\
\hline$>4$ weeks & $18(32)$ & $7(33)$ & $5(24)$ & $6(40)$ & \\
\hline$>6$ weeks & $21(37)$ & $8(38)$ & $8(38)$ & $5(33)$ & \\
\hline$>8$ weeks & $18(32)$ & $6(29)$ & $8(38)$ & $4(27)$ & \\
\hline \multicolumn{5}{|c|}{ AKI duration (not on dialysis)—n (\%) } & 0.78 \\
\hline$>4$ weeks & $8(14)$ & $2(10)$ & $3(14)$ & $3(20)$ & \\
\hline$>6$ weeks & $7(12)$ & $3(14)$ & $1(5)$ & $3(20)$ & \\
\hline$>8$ weeks & $25(44)$ & $12(57)$ & $9(43)$ & $4(27)$ & \\
\hline Never & $17(30)$ & $4(19)$ & $8(38)$ & $5(33)$ & \\
\hline \multicolumn{5}{|c|}{ AKI GFR threshold-n (\%) } & 0.64 \\
\hline$<40 \mathrm{~mL} / \mathrm{min}$ & $7(12)$ & $4(19)$ & $3(14)$ & 0 & \\
\hline$<30 \mathrm{~mL} / \mathrm{min}$ & $11(19)$ & $5(24)$ & $5(24)$ & $1(7)$ & \\
\hline$<25 \mathrm{~mL} / \mathrm{min}$ & $3(5)$ & $1(5)$ & $1(5)$ & $1(7)$ & \\
\hline$<20 \mathrm{~mL} / \mathrm{min}$ & $9(16)$ & $3(14)$ & $3(14)$ & $3(20)$ & \\
\hline Not applicable & $27(47)$ & $8(38)$ & $9(43)$ & $10(67)$ & \\
\hline \multicolumn{5}{|c|}{ CKD GFR threshold-n (\%) } & 0.61 \\
\hline$<40 \mathrm{~mL} / \mathrm{min}$ & $14(25)$ & $5(24)$ & $5(24)$ & $4(27)$ & \\
\hline$<30 \mathrm{~mL} / \mathrm{min}$ & $30(53)$ & $12(57)$ & $12(57)$ & $6(40)$ & \\
\hline$<25 \mathrm{~mL} / \mathrm{min}$ & $4(7)$ & 1 (5) & $2(10)$ & $1(7)$ & \\
\hline$<20 \mathrm{~mL} / \mathrm{min}$ & $7(12)$ & $2(10)$ & $2(10)$ & $3(20)$ & \\
\hline Not applicable & $2(4)$ & $1(5)$ & 0 & $1(7)$ & \\
\hline
\end{tabular}

MELD = model for end-stage liver disease; SLK = simultaneous liver-kidney transplant; $A K I=$ acute kidney injury; GFR = glomerular filtration rate; $C K D=$ chronic kidney disease; $N / A=$ not applicable.

Data based on OPTN 2002-2010 in adult patients receiving deceased donor liver transplantation (http://optn.transplant.hrsa.gov)

${ }^{1}$ Low MELD regions: Regions 3 (Alabama, Arkansas, Florida, Georgia, Louisiana), 6 (Oregon, Washington), 10 (Indiana, Michigan, Ohio), 11 (Kentucky, North \& South Carolina, Tennessee, Virginia).

${ }^{2}$ Average MELD regions: Regions 4 (Oklahoma, Texas), 7 (Illinois, Minnesota, Wisconsin), and 8 (Colorado, lowa, Kansas, Missouri, Nebraska)

${ }^{3}$ High MELD regions: Regions 1 (Connecticut, Massachusetts), 5 (California, Arizona, Utah), 9 (New York).

organ failure may jeopardize the life of the liver recipient. In addition, kidney transplant candidates who are placed on the waiting list following LT constitute a significant and more rapidly growing cohort with higher mortality rates in comparison to patients without a previous organ transplant $(24,25)$.

The current published recommendations and OPTN proposal for SLK have outlined specific criteria for dialysis duration, $A K I$ and GFR levels for potential candidates without any consideration for the etiology of renal dysfunction. As evidenced by the national survey results, less than $50 \%$ of centers currently follow these suggested algorithms. For candidates with $\mathrm{AKI}$, significant center variation exists in the minimum duration of dialysis, with $>30 \%$ having criteria that are either less than or greater than the 6 weeks recommended. Furthermore, a significant percentage of centers do not consider any patient with AKI for SLK unless they are on dialysis. Centers that use less stringent dialysis duration criteria (4weeks) also tended to perform more SLK and nondialysis AKI duration was generally shorter and the GFR threshold for CKD was higher This suggests that the observed variation is not random but rather reflects a true spectrum of opinions and practice. The diversity of responses may be impacted by factors such as various definition of AKI used, in addition to varied approaches used by centers in deciding when to initiate dialysis in liver transplant candidates with renal dysfunction.

The cause of renal dysfunction, however, is not included in the current published or proposed criteria for SLK. A recent study by Nadim et al. however has demonstrated that for the same degree of $\mathrm{AKI}$, patients with acute tubular necrosis as the cause of $A K I$ at the time of transplant had higher mortality and worse renal outcomes at 5 years in comparison to patients with hepatorenal syndrome (26). As a result, the decision to do SLK versus LTA in centers may not solely be made by duration of $\mathrm{AKI}$, with or without dialysis, and centers may also be factoring etiology of $\mathrm{AKI}$ in their decision making.

Findings from the survey also demonstrated significant regional variation in SLK practices. Somewhat surprisingly, this variation did not necessarily correlate with the 
Table 7: Practice patterns and relation to and criteria for dialysis duration

\begin{tabular}{|c|c|c|c|}
\hline & \multicolumn{2}{|c|}{$\begin{array}{c}\text { Dialysis duration in } \\
\text { weeks }\end{array}$} & \multirow[b]{2}{*}{$\mathrm{p}$-Value } \\
\hline & $\begin{array}{c}>4 \text { weeks } \\
(n=18)\end{array}$ & $\begin{array}{c}>6 \text { weeks } \\
(\mathrm{n}=39)\end{array}$ & \\
\hline \multicolumn{3}{|c|}{ Annual volume of liver transplant-n (\%) } & 0.78 \\
\hline$>100$ & $4(22)$ & $10(26)$ & \\
\hline$<100$ & $14(78)$ & $29(74)$ & \\
\hline \multicolumn{3}{|l|}{ Annual volume of SLK-n (\%) } & 0.05 \\
\hline$>10$ & $4(22)$ & $2(5)$ & \\
\hline$<10$ & $14(78)$ & $37(95)$ & \\
\hline \multicolumn{3}{|c|}{ AKI duration, not on dialysis-n (\%) } & 0.0003 \\
\hline$>4$ weeks & 7 (39) & 1 (3) & \\
\hline$>6$ weeks & $11(61)$ & $38(97)$ & \\
\hline \multicolumn{3}{|l|}{ AKI GFR threshold-n (\%) } & 0.64 \\
\hline$>25 \mathrm{~mL} / \mathrm{min}$ & 7 (39) & $11(28)$ & \\
\hline$<25 \mathrm{~mL} / \mathrm{min}$ & $11(61)$ & $28(72)$ & \\
\hline \multicolumn{3}{|l|}{ CKD GFR threshold-n (\%) } & 0.02 \\
\hline$>30 \mathrm{~mL} / \mathrm{min}$ & $8(44)$ & $6(15)$ & \\
\hline$<30 \mathrm{~mL} / \mathrm{min}$ & $10(57)$ & $33(85)$ & \\
\hline
\end{tabular}

SLK = simultaneous liver-kidney transplant; $A K I=$ acute kidney injury; GFR = glomerular filtration rate; $C K D=$ chronic kidney disease.

proportion of SLK done in the region. For example, while a high proportion of SLKs have been performed in regions 1 , 5 and 7 based on OPTN data, these regions did not necessarily have the most liberal SLK criteria, that is, dialysis or AKI duration $>4$ weeks. Given the significant variation in median MELD scores across regions, the regional variation in SLK is likely to reflect differences in supply and demand of liver grafts.

Few studies exist on the natural history of renal failure in the setting of liver failure and subsequent LT that can promote a universal algorithm that serves the patient yet preserves kidney resources. Observational studies comparing SLK and LTA outcomes based on single center or registry data are plagued by significant selection bias and registry data limitations. Although this is the first study to address the problem of the wide variability in SLK practices, caution should be heeded when attempting to generalize this study's findings. Our results were obtained by surveying medical directors and not by prospective data collection and thus, as with all surveys, recall bias and other limitations apply. The results of this survey suggest that centers are not confident that the published guidance is sufficiently evidence-based to direct practice. To be able to suggest a usable algorithm for SLK, it will be important to develop a series of multicenter longitudinal observational studies to help physicians better understand the impact of pretransplant renal dysfunction on posttransplant outcomes.

\section{Acknowledgments}

The authors would like to thank all the Medical Directors who completed the survey and Lauren Brown for her help on the statistical analysis of the data.

\section{Disclosure}

The authors of this manuscript have no conflicts of interest to disclose as described by the American Journal of Transplantation.

\section{References}

1. Hampel H, Bynum GD, Zamora E, El-Serag HB. Risk factors for the development of renal dysfunction in hospitalized patients with cirrhosis. Am J Gastroenterol 2001; 96: 2206-2210.

2. Wu CC, Yeung LK, Tsai WS, et al. Incidence and factors predictive of acute renal failure in patients with advanced liver cirrhosis. Clin Nephrol 2006; 65: 28-33.

3. Nair S, Verma S, Thuluvath PJ. Pretransplant renal function predicts survival in patients undergoing orthotopic liver transplantation. Hepatology 2002; 35: 1179-1185.

4. Pawarode A, Fine DM, Thuluvath PJ. Independent risk factors and natural history of renal dysfunction in liver transplant recipients. Liver Transpl 2003; 9: 741-747.

5. Markmann JF, Markmann JW, Markmann DA, et al. Preoperative factors associated with outcome and their impact on resource use in 1148 consecutive primary liver transplants. Transplantation 2001; 72: 1113-1122.

6. Lafayette RA, Pare G, Schmid CH, King AJ, Rohrer RJ, Nasraway SA. Pretransplant renal dysfunction predicts poorer outcome in liver transplantation. Clin Nephrol 1997; 48: 159-164.

7. Campbell MS, Kotlyar DS, Brensinger CM, et al. Renal function after orthotopic liver transplantation is predicted by duration of pretransplantation creatinine elevation. Liver Transpl 2005; 11: 10481055.

8. Bilbao I, Charco R, Balsells J, et al. Risk factors for acute renal failure requiring dialysis after liver transplantation. Clin Transplant 1998; 12: 123-129.

9. Brown RS Jr., Lombardero M, Lake JR. Outcome of patients with renal insufficiency undergoing liver or liver-kidney transplantation. Transplantation 1996; 62: 1788-1793.

10. Gonwa TA, Klintmalm GB, Levy M, Jennings LS, Goldstein RM, Husberg BS. Impact of pretransplant renal function on survival after liver transplantation. Transplantation 1995; 59: 361-365.

11. Gonwa TA, Morris CA, Goldstein RM, Husberg BS, Klintmalm GB. Long-term survival and renal function following liver transplantation in patients with and without hepatorenal syndromeexperience in 300 patients. Transplantation 1991; 51: 428-430.

12. Seu P, Wilkinson AH, Shaked A, Busuttil RW. The hepatorenal syndrome in liver transplant recipients. Am Surg 1991; 57: 806809.

13. Pham PT, Pham PC, Wilkinson AH. The kidney in liver transplantation. Clin Liver Dis 2000; 4: 567-590.

14. Wilkinson $A H$, Cohen DJ. Renal failure in the recipients of nonrenal solid organ transplants. J Am Soc Nephrol 1999; 10: 11361144.

15. Gonwa TA, McBride MA, Anderson K, Mai ML, Wadei H, Ahsan $N$. Continued influence of preoperative renal function on outcome of orthotopic liver transplant (OLTX) in the US: Where will MELD lead us? Am J Transplant 2006; 6: 2651-2659.

16. Jeyarajah DR, Gonwa TA, McBride M, et al. Hepatorenal syndrome: combined liver kidney transplants versus isolated liver transplant. Transplantation 1997; 64: 1760-1765.

17. Narayanan Menon KV, Nyberg SL, Harmsen WS, et al. MELD and other factors associated with survival after liver transplantation. Am J Transplant 2004; 4: 819-825. 


\section{SLK Practice in US Transplant Centers}

18. Bahirwani R, Campbell MS, Siropaides $T$, et al. Transplantation: Impact of pretransplant renal insufficiency. Liver Transpl 2008; 14 : 665-671.

19. Northup PG, Argo CK, Bakhru MR, Schmitt TM, Berg CL, Rosner $\mathrm{MH}$. Pretransplant predictors of recovery of renal function after liver transplantation. Liver Transpl 2010; 16: 440-446.

20. Ruiz $R$, Kunitake $H$, Wilkinson $A H$, et al. Long-term analysis of combined liver and kidney transplantation at a single center. Arch Surg 2006; 141: 735-741.

21. Cabezuelo JB, Ramirez P, Rios A, et al. Risk factors of acute renal failure after liver transplantation. Kidney Int. 2006; 69: 1073-1080.

22. Davis $C L$, Feng $S$, Sung $R$, et al. Simultaneous liver-kidney transplantation: Evaluation to decision making. Am J Transplant 2007; 7: 1702-1709.
23. Eason JD, Gonwa TA, Davis CL, Sung RS, Gerber D, Bloom RD. Proceedings of Consensus Conference on Simultaneous Liver Kidney Transplantation (SLK). Am J Transplant 2008; 8: 22432251.

24. Srinivas TR, Stephany BR, Budev M, et al. An emerging population: Kidney transplant candidates who are placed on the waiting list after liver, heart, and lung transplantation. Clin J Am Soc Nephrol 2010; 5: 1881-1886. PMCID: 2974390.

25. Cassuto JR, Reese PP, Sonnad S, et al. Wait list death and survival benefit of kidney transplantation among nonrenal transplant recipients. Am J Transplant 2010; 10: 2502-2511. PMCID: 2966021.

26. Nadim MK, Genyk YS, Tokin C, et al. Impact of etiology of acute kidney injury on outcomes following liver transplantation: Acute tubular necrosis versus hepatorenal syndrome. Liver Transpl 2012; 18: 539-548. 